\title{
Treosulfan-fludarabine-thiotepa-based conditioning treatment before allogeneic hematopoietic stem cell transplantation for pediatric patients with hematological malignancies
}

\author{
Krzysztof Kalwak $\mathbb{D}^{1} \cdot$ Monika Mielcarek ${ }^{1} \cdot$ Katharine Patrick ${ }^{2} \cdot$ Jan Styczynski $\mathbb{D}^{3} \cdot$ Peter Bader ${ }^{4}$.

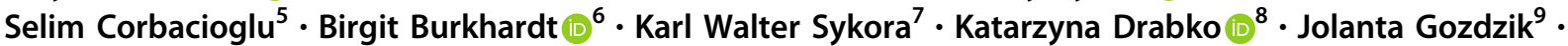

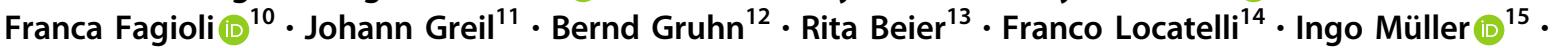 \\ Paul Gerhardt Schlegel ${ }^{16} \cdot$ Petr Sedlacek $^{17} \cdot$ Klaus Daniel Stachel $^{18} \cdot$ Claudia Hemmelmann $^{19} \cdot$ Ann-Kristin Möller $^{19}$. \\ Joachim Baumgart ${ }^{19} \cdot$ Ajay Vora $^{20}$
}

Received: 23 July 2019 / Revised: 4 March 2020 / Accepted: 10 March 2020 / Published online: 20 March 2020

(c) The Author(s) 2020. This article is published with open access

\begin{abstract}
Treosulfan-based conditioning prior to allogeneic transplantation has been shown to have myeloablative, immunosuppressive, and antineoplastic effects associated with reduced non-relapse mortality (NRM) in adults. Therefore, we prospectively evaluated the safety and efficacy of treosulfan-based conditioning in children with hematological malignancies in this phase II trial. Overall, 65 children with acute lymphoblastic leukemia (35.4\%), acute myeloid leukemia (44.6\%), myelodysplastic syndrome $(15.4 \%)$, or juvenile myelomonocytic leukemia (4.6\%) received treosulfan intravenously at a dose of $10 \mathrm{mg} / \mathrm{m}^{2} /$ day $(7.7 \%), 12 \mathrm{~g} / \mathrm{m}^{2} /$ day $(35.4 \%)$, or $14 \mathrm{~g} / \mathrm{m}^{2} /$ day $(56.9 \%)$ according to their individual body surface area in combination with fludarabine and thiotepa. The incidence of complete donor chimerism at day +28 was $98.4 \%$ with no primary and only one secondary graft failure. At 36 months, NRM was only $3.1 \%$, while relapse incidence was $21.7 \%$, and overall survival was $83.0 \%$. The cumulative incidence of acute graft-vs.-host disease was $45.3 \%$ for grades I-IV and $26.6 \%$ for grades II-IV. At 36 months, $25.8 \%$ overall and $19.4 \%$ moderate/severe chronic graft-vs.-host disease were reported. These data confirm the safe and effective use of treosulfan-based conditioning in pediatric patients with hematological malignancies. Therefore, treosulfan/fludarabine/thiotepa can be recommended for myeloablative conditioning in children with hematological malignancies.
\end{abstract}

\section{Introduction}

Children with hematological malignancies routinely undergo either busulfan- or fractionated TBI-based myeloablative conditioning regimens prior to allogenic hematopoietic stem cell transplantation (alloHSCT). However, both regimens are associated with a considerable risk of acute and late serious adverse events (AEs) [1-5]. Clinical studies, including prospective phase III trials in adults with

Supplementary information The online version of this article (https:// doi.org/10.1038/s41409-020-0869-6) contains supplementary material, which is available to authorized users.

Krzysztof Kalwak

krzysztof.kalwak@gmail.com

Extended author information available on the last page of the article
AML and MDS, have shown that treosulfan-based conditioning has myeloablative, immunosuppressive, and antineoplastic effects associated with a low non-relapse mortality (NRM) [6-11]. Furthermore, several reports have been published that show an indication for treosulfan-based conditioning in children undergoing alloHSCT for nonmalignant and malignant disorders [12-21]. In addition, pharmacokinetic (PK) investigations on treosulfan in children have been conducted in order to derive dose recommendations for all pediatric age groups [22-25]. We therefore, prospectively evaluated treosulfan/fludarabine conditioning in pediatric patients with hematological malignancies during this extended clinical phase II trial. Herein, we strictly applied an individual body surface area (BSA)-adapted treosulfan dosing [26] with the option of administrating an intensified regimen by additional thiotepa infusion. 


\section{Patients and methods}

\section{Patient eligibility}

Between November 2014 and July 2015, 70 children (aged 28 days to 17 years) with acute lymphoblastic leukemia (ALL), acute myeloid leukemia (AML), myelodysplastic syndrome (MDS), or juvenile myelomonocytic leukemia (JMML) were enrolled in this prospective non-randomized phase II trial at 18 transplantation sites in five European countries. Written informed consent on all aspects of the study was obtained from all children and/or their legal guardians before enrollment. The study was approved by the responsible independent ethics committees and competent authorities and was performed in accordance with the Declaration of Helsinki, as well as Good Clinical Practice guideline. Safety and outcome parameters of all surviving patients were analyzed after a 36 months follow-up period focusing on the 65 patients who were additionally treated with thiotepa. The 5 out of 70 patients, who received treosulfan and fludarabine only, were excluded from the statistical analysis reported here. However, the key findings for all 70 trial patients (including the five patients conditioned only with treosulfan/fludarabine) are provided in Fig. S1 in the online supplementary.

\section{Donors and grafts}

Either human leucocyte antigens (HLA)-identical siblings (MSD), matched family donors, or matched unrelated donors were eligible donors (Table 1). An HLA match was defined as at least a 9/10 allele-matched after high-
Table 1 Summary of demographic data and transplant characteristics by disease.

\begin{tabular}{|c|c|c|c|c|c|}
\hline & \multicolumn{5}{|l|}{ Disease } \\
\hline & $\operatorname{ALL}(N=23)$ & $\operatorname{AML}(N=29)$ & $\operatorname{MDS}(N=10)$ & JMML $(N=3)$ & Overall $(N=65)$ \\
\hline \multicolumn{6}{|l|}{$\operatorname{Sex}[n(\%)]$} \\
\hline Male & $15(65.2 \%)$ & $19(65.5 \%)$ & $5(50.0 \%)$ & $3(100.0 \%)$ & $42(64.6 \%)$ \\
\hline Female & $8(34.8 \%)$ & $10(34.5 \%)$ & $5(50.0 \%)$ & $0(0.0 \%)$ & $23(35.4 \%)$ \\
\hline \multicolumn{6}{|l|}{ Age [years] } \\
\hline Mean (SD) & $10.5(5.6)$ & $8.2(5.6)$ & $11.6(5.7)$ & $2.0(2.0)$ & $9.3(5.8)$ \\
\hline Median & 12.0 & 8.0 & 14.0 & 2.0 & 11.0 \\
\hline Min., Max. & 1,17 & 0,17 & 1,17 & 0,4 & 0,17 \\
\hline \multicolumn{6}{|l|}{ ICH age group $[n(\%)]$} \\
\hline 28 days to 23 months & $2(8.7 \%)$ & $4(13.8 \%)$ & $1(10.0 \%)$ & $1(33.3 \%)$ & $8(12.3 \%)$ \\
\hline $2-11$ years & $7(30.4 \%)$ & $14(48.3 \%)$ & $2(20.0 \%)$ & $2(66.7 \%)$ & $25(38.5 \%)$ \\
\hline $12-17$ years & $14(60.9 \%)$ & $11(37.9 \%)$ & $7(70.0 \%)$ & $0(0.0 \%)$ & $32(49.2 \%)$ \\
\hline \multicolumn{6}{|l|}{ Number of HSCT $[n(\%)]$} \\
\hline 1 st & $22(95.7 \%)$ & $28(96.6)$ & $8(80)$ & $2(66.7 \%)$ & $60(92.3 \%)$ \\
\hline 2nd & $1(4.3 \%)$ & $1(3.4)$ & $2(20)$ & $1(33.3 \%)$ & $5(7.7 \%)$ \\
\hline \multicolumn{6}{|c|}{ Number of complete remission $[n(\%)]^{\mathrm{a}}$} \\
\hline 1. $\mathrm{CR}$ & $16(69.6 \%)$ & $25(86.2 \%)$ & na & na & $41(63.1 \%)$ \\
\hline 2. $\mathrm{CR}$ & $7(30.4 \%)$ & $3(10.3 \%)$ & na & na & $10(15.4 \%)$ \\
\hline 3. CR (or higher) & $0(0.0)$ & $1(3.4 \%)$ & na & na & $1(1.5 \%)$ \\
\hline \multicolumn{6}{|c|}{ Secondary origin of malignancy $[n(\%)]$} \\
\hline Yes & $1(4.3)$ & $0(0.0)$ & $4(40)$ & $0(0.0)$ & $5(7.7)$ \\
\hline \multicolumn{6}{|l|}{ Treosulfan dose $[n(\%)]$} \\
\hline $10 \mathrm{~g} / \mathrm{m}^{2} /$ day $-6,-5,-4$ & $1(4.3 \%)$ & $3(10.3 \%)$ & $0(0.0 \%)$ & $1(33.3 \%)$ & $5(7.7 \%)$ \\
\hline $12 \mathrm{~g} / \mathrm{m}^{2} /$ day $-6,-5,-4$ & $5(21.7 \%)$ & $13(44.8 \%)$ & $3(30.0 \%)$ & $2(66.7 \%)$ & $23(35.4 \%)$ \\
\hline $14 \mathrm{~g} / \mathrm{m}^{2} /$ day $-6,-5,-4$ & $17(73.9 \%)$ & $13(44.8 \%)$ & $7(70.0 \%)$ & $0(0.0 \%)$ & $37(56.9 \%)$ \\
\hline \multicolumn{6}{|l|}{ Donor type $[n(\%)]$} \\
\hline Matched sibling & $6(26.1 \%)$ & $4(13.8 \%)$ & $1(10.0 \%)$ & $0(0.0 \%)$ & $11(16.9 \%)$ \\
\hline Matched family & $0(0.0 \%)$ & $1(3.4 \%)$ & $0(0.0 \%)$ & $0(0.0 \%)$ & $1(1.5 \%)$ \\
\hline Matched unrelated & $17(73.9 \%)$ & $24(82.8 \%)$ & $9(90.0 \%)$ & $3(100.0 \%)$ & $53(81.5 \%)$ \\
\hline \multicolumn{6}{|l|}{ Source $[n(\%)]$} \\
\hline Bone marrow & $14(60.9 \%)$ & $13(44.8 \%)$ & $3(30.0 \%)$ & $3(100.0 \%)$ & $33(50.8 \%)$ \\
\hline Peripheral blood & $9(39.1 \%)$ & $16(55.2 \%)$ & $7(70.0 \%)$ & $0(0.0 \%)$ & $32(49.2 \%)$ \\
\hline
\end{tabular}

$A L L$ acute lymphoblastic leukaemia, $A M L$ acute myeloid leukaemia, MDS myelodysplastic syndrome, $J M M L$ juvenile myelomonocytic leukaemias, $I C H$ International Council of Harmonization, Max. maximum, Min. minimum, $N$ number of subjects, $n$ number of subjects in category, $S D$ standard deviation, na not applicable.

${ }^{a}$ For ALL and AML subjects only. 
resolution four-digit typing in HLA-A*, $\mathrm{B}^{*}, \mathrm{C}^{*}$ and DRB1* and DQB1*.

\section{Conditioning regimen and supportive care}

All patients received an individualized BSA-adapted intravenous (IV) treosulfan dose on days -6 to -4 , i.e., BSA of $\leq 0.5 \mathrm{~m}^{2}$ received $10 \mathrm{~g} / \mathrm{m}^{2} /$ day; of $>0.5-1.0 \mathrm{~m}^{2}$ received $12 \mathrm{~g} / \mathrm{m}^{2} /$ day; and of $>1.0 \mathrm{~m}^{2}$ received $14 \mathrm{~g} / \mathrm{m}^{2} /$ day. Subsequently, fludarabine $30 \mathrm{mg} / \mathrm{m}^{2} /$ day IV was given from day -7 to day -3 (total dose: $150 \mathrm{mg} / \mathrm{m}^{2}$ ). At the investigator's discretion, thiotepa $2 \times 5 \mathrm{mg} / \mathrm{kg} /$ day IV was additionally given on day -2 to 65 patients (total dose: $10 \mathrm{mg} / \mathrm{kg}$ ). Allogeneic hematopoietic stem cells obtained either from peripheral blood or from bone marrow were given at day 0. Supportive care, including GvHD prophylaxis and treatment, was performed according to center-specific guidelines.

\section{Endpoints and definitions}

The objective of this phase II trial was to describe the safety and efficacy of treosulfan administered as part of a standardized fludarabine-containing conditioning treatment and to contribute to a PK model. Clinical endpoints included engraftment and complete donor-type chimerism (defined as $\geq 95 \%$ donor cells), NRM, disease relapse/progression (RI), relapse/progression-free survival (RFS/PFS), acute/chronic GvHD, GvHD-free and relapse/progression-free survival (GRFS) [27], cGvHD-free and relapse/progression-free survival (CRFS) [27], and overall survival (OS).

NRM is defined as the probability of dying without previous occurrence of a relapse/progression of the underlying disease. Relapse/progression and graft failures are considered competing events. For estimation of GRFS, events were defined as acute GvHD of at least grade III, moderate or severe chronic GvHD, and relapse/progression or death (whichever occurred first). For CGRFS, events were defined as moderate or severe chronic GvHD, relapse/progression or death (whichever occurred first). All AEs except hepatic sinusoidal obstruction syndrome (HSOS) and hepatic toxicities were based on the Common Terminology Criteria for Adverse Events (CTCAE, version 4.03) and evaluated until 100 days after alloHSCT. HSOS was evaluated according to Jones et al. [28] and hepatic toxicities according to Bearman [29]. Furthermore, treosulfan concentrations in plasma from each patient were analyzed to calculate PK parameters in a subset of patients. Blood samples were taken immediately after treosulfan infusion and thereafter within 15-30 min, 1-2 h, 3-6h, and 7-8h. Further details of bioanalytical methods and the model-based parameter calculation have been previously described $[26,30]$.

\section{Statistical considerations}

Descriptive analyses were performed using frequency, mean, standard deviation, median, and range, as appropriate. All time to event endpoints were measured from the day of HSCT (except for cGvHD, which started 100 days after HSCT) to the time of event or competing event, if applicable. Patients alive without event (or competing event) were censored at the last follow-up or at day +100 after HSCT for aGvHD. Kaplan-Meier estimates were used for calculating OS, GRFS, and CRFS. Cumulative incidences were used for estimating NRM, RI, aGvHD, and conditional cumulative incidences for neutrophil/leukocyte/ platelet engraftment. Competing events were as follows: relapse/progression and graft failure for NRM; deaths without relapse/progression and graft failure for RI; death, relapse/progression, and graft failure within 100 days after the end of HSCT for aGvHD; death, disease relapse/progression, or the use of rescue therapies for engraftment.

Any changes in single laboratory values were documented separately instead of being included in the $\mathrm{AE}$ analysis. Non-compartmental methodology was applied for the PK analysis of treosulfan. Based on the individual plasma concentration-time data, the following parameters were determined using the actual sampling times for treosulfan: $C_{\max }, t_{\max }, \mathrm{AUC}_{\text {last }}, \mathrm{AUC}_{\infty}, t_{1 / 2}$ term, $\mathrm{CL}$, and $V_{d}$. Mean and standard deviations were calculated for all PK parameters, except for $t_{\max }$, for which the median and range were computed.

This trial was descriptive in nature, thus, $p$ values (two sided) were explorative, based on a significance level of 0.1 . The data were analyzed using Pearson chi-square test for chimerism, the log-rank test for OS, GRFS, and CRFS, and the Gray test for NRM, RI, a/cGvHD.

All analyses were predefined in the statistical analysis plan. SAS software (version 9.4; SAS, Cary, NC, USA) was used for statistical analyses.

\section{Results}

\section{Demographics}

Sixty-five pediatric Caucasian patients (aged 28 days to 17 years, median 11 years) with ALL [35.4\%], AML [44.6\%], MDS [15.4\%], or JMML [4.6\%] were conditioned with treosulfan, fludarabine, and thiotepa. Nearly all of the ALL and AML patients were in first or second complete remission and had received their first alloHSCT procedure. Patients with MDS were classified as having refractory anemia with excess blasts $(50 \%)$ or refractory cytopenia $(40 \%)$. Children received alloHSCT between November 2014 and July 2015. 
The median follow-up was 41.8 months (range for surviving patients: $24.2-57.5$ months).

Depending on their individual BSA, patients received treosulfan IV at a dose of $10 \mathrm{~g} / \mathrm{m}^{2} /$ day $(7.7 \%), 12 \mathrm{~g} / \mathrm{m}^{2} /$ day $(35.4 \%)$, or $14 \mathrm{~g} / \mathrm{m}^{2} /$ day $(56.9 \%)$. Treosulfan was combined with fludarabine and thiotepa in 65 of 70 patients at the investigators' discretion (Table 1).

\section{Outcomes}

\section{Engraftment, graft failure, and chimerism}

The number of patients achieving reconstitution of granulopoiesis was $64(98.5 \%)$. One patient (1.4\%) died before engraftment 15 days after alloHSCT. The maximum conditional cumulative incidence of engraftment reached was 100\% (90\% CI: 97.7, 100.0) 43 days after HSCT. No patient experienced primary graft failure, and one patient (1.4\%) with ALL had decreased neutrophils and leukocytes counts, but presented $100 \%$ donor chimerism, for which the patient received a stem cell boost 113 days post transplant.

The incidence of complete donor-type chimerism at visit day +28 was $98.4 \%$ (90\% CI: $92.8,99.90)$, at visit day +100 the incidence was $92.2 \%$ (90\% CI: $84.3,96.9$ ), and at 12 months the incidence was $92.6 \%$ (90\% CI: 83.8, 97.4) (Table 2). In exploratory subgroup analyses, a statistically significant influence on complete chimerism of underlying

Table 2 Incidence of complete donor-type chimerism.

\begin{tabular}{ll}
\hline & Treosulfan \\
\hline Subjects at risk at day +28 visit $^{\mathrm{a}}$ & $N=64$ \\
$\quad$ Subjects with complete chimerism at day +28 visit & $63(98.4)$ \\
{$[n(\%)]$} & \\
$90 \%$ CI & $(92.8,99.9)$ \\
Subjects without information at day +28 visit & $1(1.6)$ \\
$\quad[n(\%)]$ & \\
Subjects at risk at day +100 visit $^{\mathrm{a}}$ & $N=64$ \\
$\quad$ Subjects with complete chimerism at day +100 visit & $59(92.2)$ \\
$\quad[n(\%)]$ & $(84.3,96.9)$ \\
$90 \%$ CI & $5(7.8)$ \\
Subjects without information at day +100 visit & \\
$\quad n(\%)]$ & $N=54$ \\
Subjects at risk at month 12 visit $^{\mathrm{a}}$ & $50(92.6)$ \\
Subjects with complete chimerism at month 12 visit & \\
{$[n(\%)]$} & $(83.8,97.4)$ \\
$90 \%$ CI & $2(3.7)$ \\
Subjects without information at month 12 visit & \\
{$[n(\%)]$} &
\end{tabular}

$C I$ confidence interval, $N$ number of subjects, $n$ number of subjects in category.

${ }^{\text {a }}$ Subjects are at risk if they have a chimerism examination at the day +28 , day +100 , or month 12 visit or if they have survived day +30 , day +107 , or day +379 . disease (JMML with $0 \%$ at day +100 ), as well as 2 nd alloHSCT procedure was recorded (day +100: $p<0.001$ influence of underlying disease, $p=0.0566$ 2nd HSCT). In contrast, the treosulfan dose, donor type, or patients age group did not significantly influence the incidence of complete donor-type chimerism.

\section{Non-relapse mortality and relapse/progression incidence}

Overall, the cumulative incidence of NRM at 36 months was $3.1 \%$ (90\% CI: 0.0, 6.6). One patient with AML died due to laryngeal hemorrhage 0.5 months after HSCT. A second patient with MDS died due to multi organ failure 12.3 months after HSCT. Due to the low number of events, no statistically significant difference in NRM was detected among the three different treosulfan dose groups (Fig. 1a) or within any other of the analyzed subgroups.

The cumulative incidence of relapse/progression (RI) at 36 months was $21.7 \%$ (90\% CI: 13.2, 30.1). In the subgroup analyses, no statistically significant impact was recorded for treosulfan dose, donor type, or patient's age group (Fig. 1b), but was found for underlying disease $(p<0.0001)$. Relapse incidences of ALL were 26.1\%, AML 17.2\%, MDS 0.0\%, and JMML $100 \%$. In the case of a 2nd HSCT procedure, the incidence of relapse/progression increased from 18.5 to $60.0 \%$ ( $p=0.0140)$ considering that only five patients were treated in a second procedure.

\section{Relapse/progression-free survival}

The 36-month Kaplan-Meier estimate of RFS/PFS was 73.6\% (90\% CI: 63.3, 81.5). In the exploratory subgroup analyses a statistically significant impact was recorded for 2nd HSCT (1st HSCT [76.4\%]; 2nd HSCT [40\%]; $p=$ 0.0234) and underlying disease (ALL [69.6\%], AML [79.3\%], MDS [88.9\%], JMML [0\%]; $p=0.0001)$. However, in total only three JMML patients were included in the trial. There was no difference in RFS/PFS among donor types, age groups, and the three different treosulfan dose groups (Figs. 1c and 2).

\section{Graft-vs.-host disease}

At 100 days, the cumulative incidence of acute GvHD was: 45.3\% (90\% CI: 35.1, 55.5) grades I-IV, 26.6\% (90\% CI: 17.5, 35.6) grades II-IV, and 7.8\% (90\% CI: 2.3, 13.3) grades III-IV (Table 3 ). There was no difference among the three different treosulfan dose groups (Fig. S2 in online supplementary).

The cumulative incidence of chronic GvHD at 36 months was $25.8 \%$ (90\% CI: $16.7,34.9)$ and that of moderate/ severe chronic GvHD was 19.4\% (90\% CI: 11.1, 27.7) (Table 3 and Fig. S3 in the online supplementary). The ten 
a

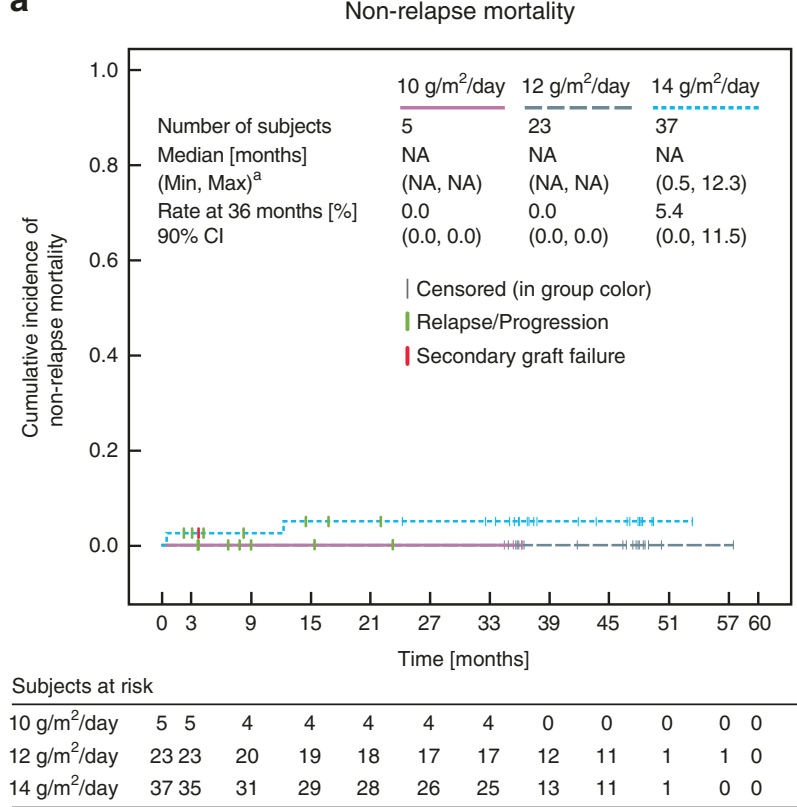

C

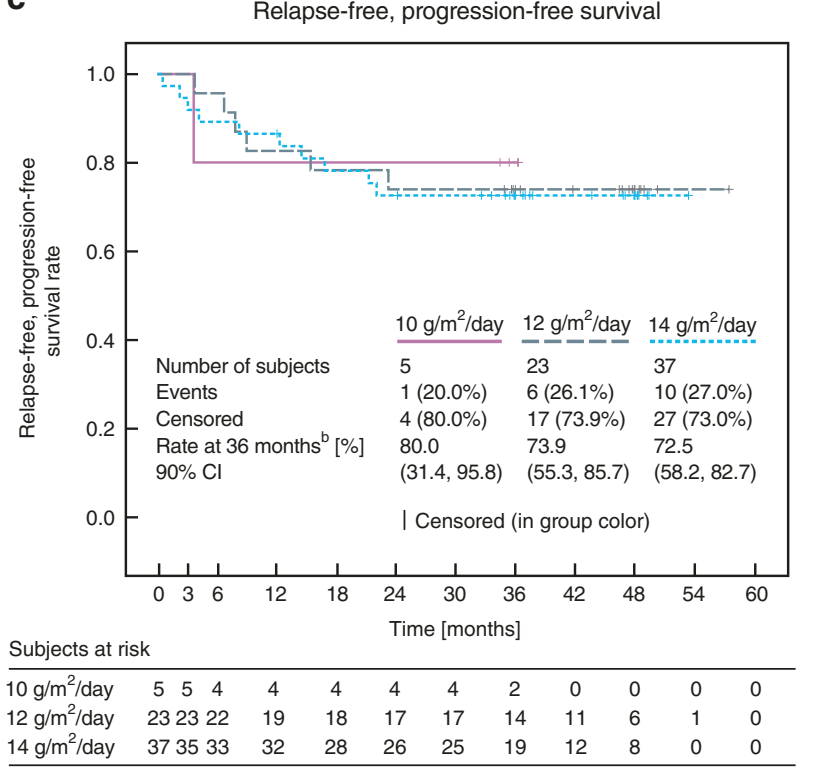

b

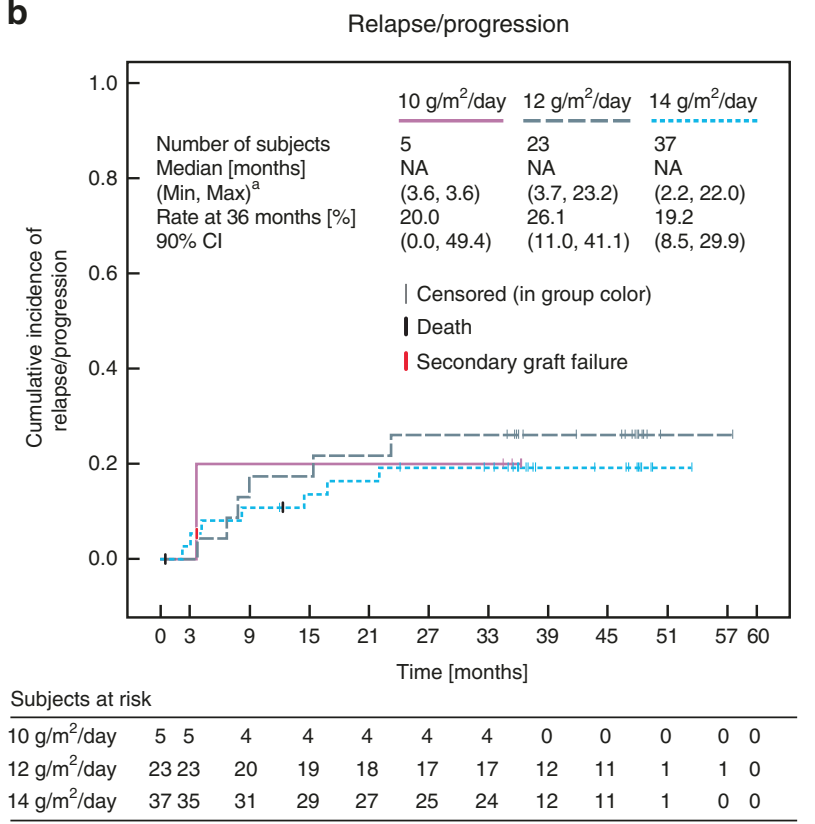

d

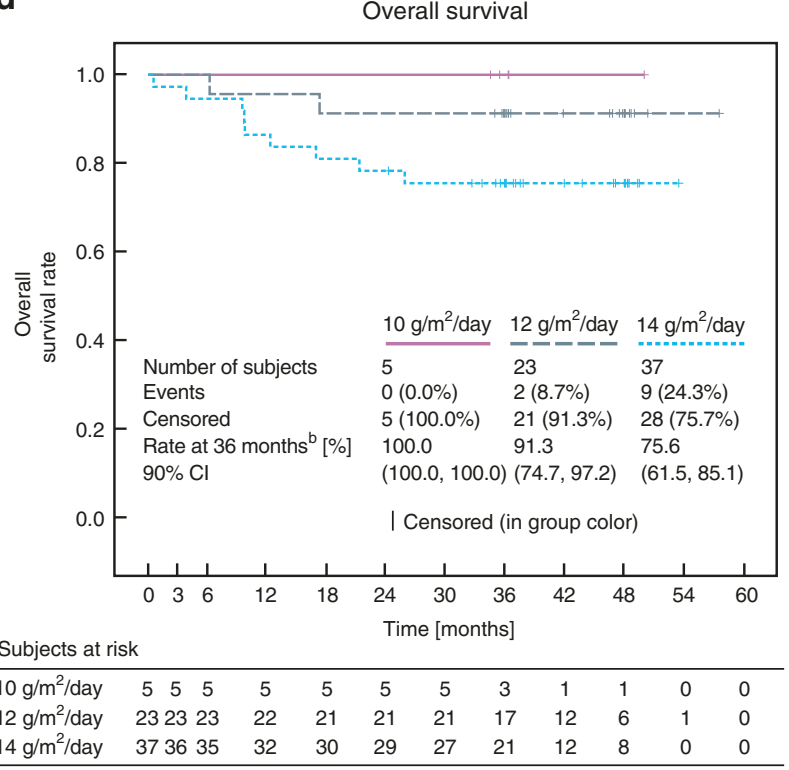

${ }^{\mathrm{a}}$ Minimum and maximum of observed event times

${ }^{\mathrm{b}}$ Based on Kaplan-Meier estimates

Fig. 1 Treosulfan dose-dependent cumulative incidence of non-relapse mortality (a), relapse/progression (b), Kaplan-Meier estimate of relapse/ progression-free survival (c) and of overall survival (d).

MDS patients experienced a higher overall and moderate/ severe chronic GvHD incidences $(60.0 \%$ [95\% CI: 34.5, 85.5] and 52\% [90\% CI: 25.0, 79.9], respectively).

\section{GvHD-free and relapse/progression-free survival (GRFS) and cGvHD-free and relapse/progression-free survival (CRFS)}

The 36-month Kaplan-Meier estimate of GRFS was 56.7\% (90\% CI: 45.9, 66.1) (Fig. 3a). In the disease subgroups,
GRFS was 56.5\% at 36 months for ALL, $69.0 \%$ for AML, and $36.0 \%$ for MDS (JMML was not applicable). The five patients who underwent a second HSCT experienced a significantly lower incidence of GRFS with only $20.0 \%$ (90\% CI: $1.8,52.2 ; p=0.0105)$ compared with patients after their first HSCT $(59.7 \%$; 90\% CI: 48.5, 69.3).

The Kaplan-Meier estimate of CRFS at 36 months was $58.2 \%$ (90\% CI: 47.4, 67.5) (Fig. 3b). In the disease subgroups, CRFS was $60.9 \%$ for ALL, $69.0 \%$ for AML, $36 \%$ 
Fig. 2 Forest plot for relapse/ progression-free survival displaying 36 months rates by subgroups.

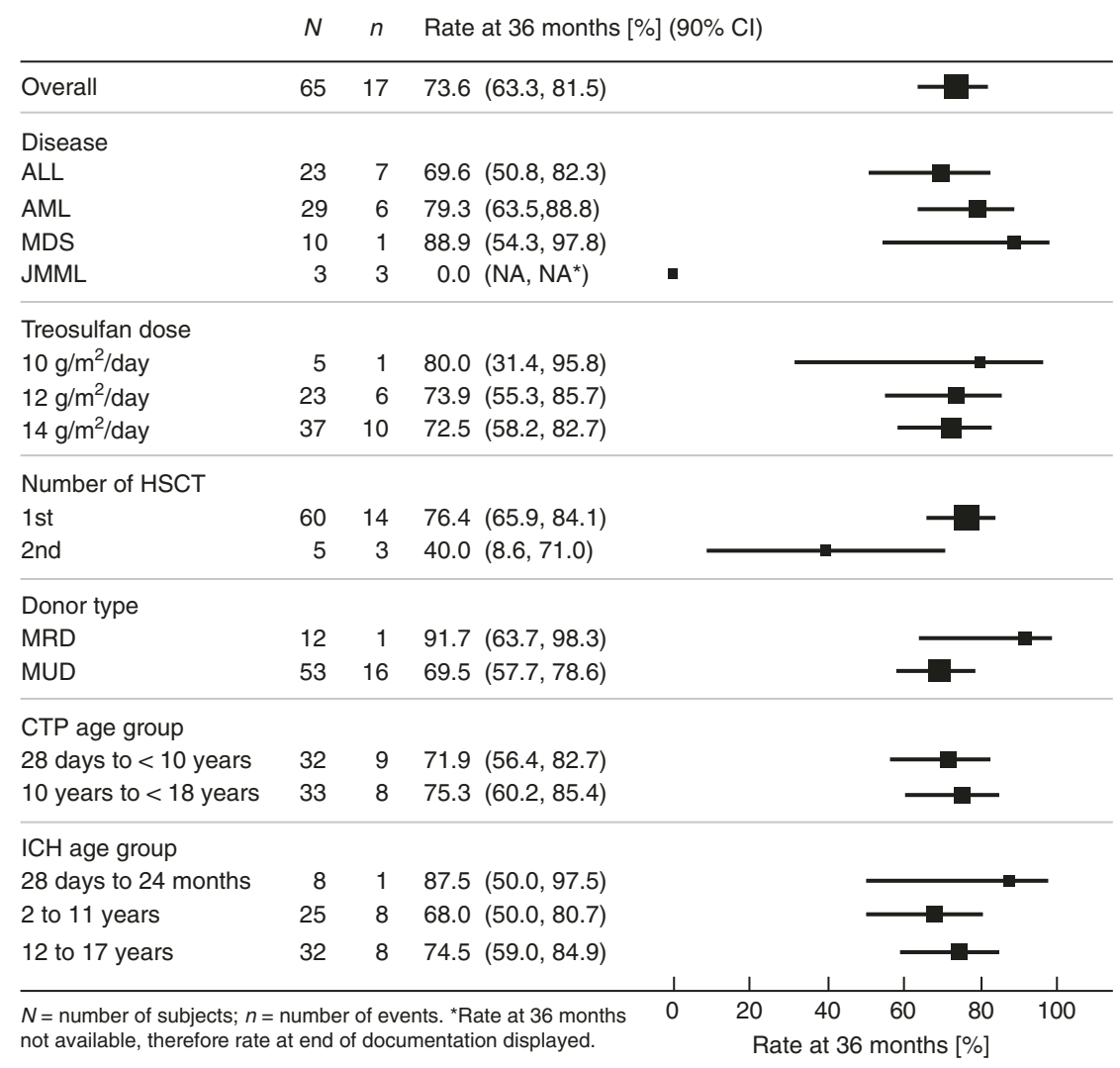

for MDS, and $0.0 \%$ for JMML patients $(p=0.0017)$. Again, CRFS was worse after the second HSCT procedure (20.0 vs. $61.4 \% ; p=0.0060$ ), while treosulfan dose, donor type, and age group did not influence this combined endpoint.

\section{Overall survival (OS)}

At the time of the final analysis, 11 patients (16.9\%) had died. The causes of these deaths were relapse/progression related in eight $(12.3 \%)$ patients, and transplantation related in three patients $(4.6 \%)$.

The median time from transplantation to death was 9.72 months (Q1, Q3: 6.18, 17.25) with a range from 0.5 to 25.8 months. The 36-month Kaplan-Meier estimate of OS after HSCT was $83.0 \%$ (90\% CI: 73.7, 89.3) (Fig. 4). OS estimates in ALL (78.3\%), AML (86.2\%), and MDS (90\%) were comparable, while of the three JMML patients two survived. OS estimates in the ICH age groups were comparable to the treosulfan dose groups. Exploratory analysis indicated that there was a higher OS in eight patients aged 28 days to 23 months $(100 \%, 90 \% \mathrm{CI}: 100,100)$ than in the 32 patients aged $12-17$ years $(74.9 \%, 90 \%$ CI: $59.5,85.1)$. Accordingly (due to the individual BSA-related dose calculation), OS was $100 \%$ in the $10 \mathrm{~g} / \mathrm{m}^{2}$ treosulfan group and $75.6 \%(90 \%$ CI: $61.5,85.1)$ in the $14 \mathrm{~g} / \mathrm{m}^{2}$ dose group (Fig. 1d). The five patients who received a 2nd HSCT had a lower OS probability at 36 months (60\%, 90\% CI: 19.1, 85.4 ) in comparison with the 60 patients who received a 1 st alloHSCT procedure $(85 \%, 90 \%$ CI: $75.4,91.0)$.

\section{Adverse events and pharmacokinetic results}

Treatment-emergent AEs were reported in 63 of 65 patients (96.9\%). The most common CTCAE terms with severity of at least grade III were mucositis-oral (43.1\%), infections and infestations - other $(30.8 \%)$, nausea and vomiting (both $16.9 \%$ ), and diarrhea $(15.4 \%)$ (Table 4$)$. Skin and subcutaneous tissue disorders of at least CTCAE grade III were reported in $12.3 \%$ of the patients. One patient $(1.4 \%)$ developed HSOS (grade II according to Jones et al. [28]) and recovered after 22 days.

A total of 290 PK samples from 54 patients were analyzed. The mean $\mathrm{AUC}_{\text {last }}( \pm \mathrm{SD})$ was comparable among the three different dose groups $\left(1686 \pm 345 \mu \mathrm{g} \mathrm{h} / \mathrm{mL}\left[10 \mathrm{~g} / \mathrm{m}^{2}\right]\right.$, $1599 \pm 33 \mu \mathrm{g} \mathrm{h} / \mathrm{mL} \quad\left[12 \mathrm{~g} / \mathrm{m}^{2}\right]$, and $1848 \pm 283 \mu \mathrm{g} \mathrm{h} / \mathrm{mL}$ $\left.\left[14 \mathrm{~g} / \mathrm{m}^{2}\right]\right)$ as evaluated in the PK subset of trial patients. In addition, the median $C_{\max }$ was comparable among the different dose or BSA groups $\left(700 \pm 218 \mu \mathrm{g} / \mathrm{mL}\left[10 \mathrm{~g} / \mathrm{m}^{2}\right]\right.$, $634 \pm 192 \mu \mathrm{g} / \mathrm{mL}\left[12 \mathrm{~g} / \mathrm{m}^{2}\right]$, and $\left.650 \pm 98 \mu \mathrm{g} / \mathrm{mL}\left[14 \mathrm{~g} / \mathrm{m}^{2}\right]\right)$ reflecting the individualized dose calculation based on BSA (Table 5). However, treosulfan plasma clearance and volume of distribution increased in the different dose groups. This observation is most likely based on the 
Table 3 Summary of cumulative incidence of acute and chronic GvHD.

\begin{tabular}{|c|c|}
\hline aGvHD & Treosulfan $(N=65)$ \\
\hline \multicolumn{2}{|l|}{ Grades I-IV } \\
\hline Subjects with event $[n(\%)]$ & $29(44.6 \%)$ \\
\hline $\begin{array}{l}\text { Cumulative incidence of acute GvHD at } \\
100 \text { days }(\%)\end{array}$ & 45.3 \\
\hline $90 \% \mathrm{CI}$ & $(35.1,55.5)$ \\
\hline \multicolumn{2}{|l|}{ Grades II-IV } \\
\hline Subjects with event $[n(\%)]$ & $17(26.2 \%)$ \\
\hline $\begin{array}{l}\text { Cumulative incidence of acute GvHD at } \\
100 \text { days }(\%)\end{array}$ & 26.6 \\
\hline $90 \% \mathrm{CI}$ & $(17.5,35.6)$ \\
\hline \multicolumn{2}{|l|}{ Grades III-IV } \\
\hline Subjects with event $[n(\%)]$ & $5(7.7 \%)$ \\
\hline $\begin{array}{l}\text { Cumulative incidence of acute GvHD at } \\
100 \text { days }(\%)\end{array}$ & 7.8 \\
\hline $90 \% \mathrm{CI}$ & $(2.3,13.3)$ \\
\hline \multicolumn{2}{|l|}{ Overall } \\
\hline Subjects with event $[n(\%)]$ & $16(25.8 \%)$ \\
\hline $\begin{array}{l}\text { Cumulative incidence of cGvHD at } \\
36 \text { months }(\%)\end{array}$ & 25.8 \\
\hline $90 \% \mathrm{CI}$ & $(16.7,34.9)$ \\
\hline \multicolumn{2}{|l|}{ Moderate/severe } \\
\hline Subjects with event $[n(\%)]$ & $12(19.4 \%)$ \\
\hline $\begin{array}{l}\text { Cumulative incidence of cGvHD at } \\
36 \text { months }(\%)\end{array}$ & 19.4 \\
\hline $90 \% \mathrm{CI}$ & $(11.1,27.7)$ \\
\hline
\end{tabular}

$C I$ confidence interval, $a G v H D$ acute graft-vs.-host disease, $c G v H D$ chronic graft-vs.-host disease, $N$ number of subjects, $n$ number of subjects in category.

different ages, and BSA of the patients represented within the different dose groups.

\section{Discussion}

After initial data on treosulfan-based conditioning in adult alloHSCT patients became available $[9,10]$, several published studies reported on the efficacy and safety of treosulfan given as part of various conditioning regimens in children $[12,13,15,16,20,31]$. Here, we report the final results of the first prospective alloHSCT trial of a treosulfan/fludarabine/thiotepa combination regimen (FTT; 65 of 70 trial patients treated) administered to children and adolescents with hematological malignancies. In this study, an individual BSA-adapted dose calculation was consistently applied for treosulfan.

The 36-month Kaplan-Meier estimates of 3.1\% for NRM, $83.0 \%$ for OS, and $73.6 \%$ for RFS/PFS compare favorably with the survival data reported for other conditioning a

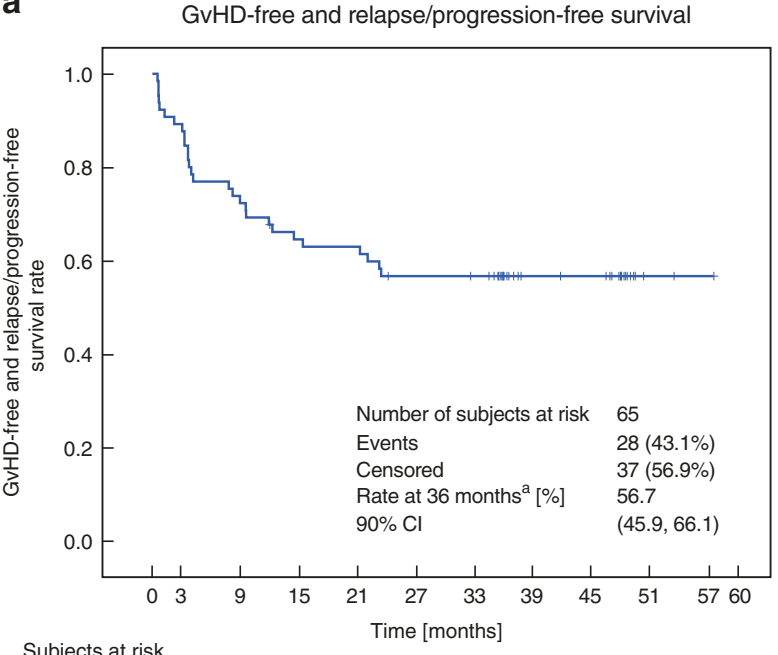

\begin{tabular}{lllllllllllll}
\hline Treosulfan & 65 & 58 & 48 & 41 & 40 & 35 & 34 & 18 & 17 & 2 & 17 & 0
\end{tabular}

b

Chronic GvHD-free and relapse/progression-free survival

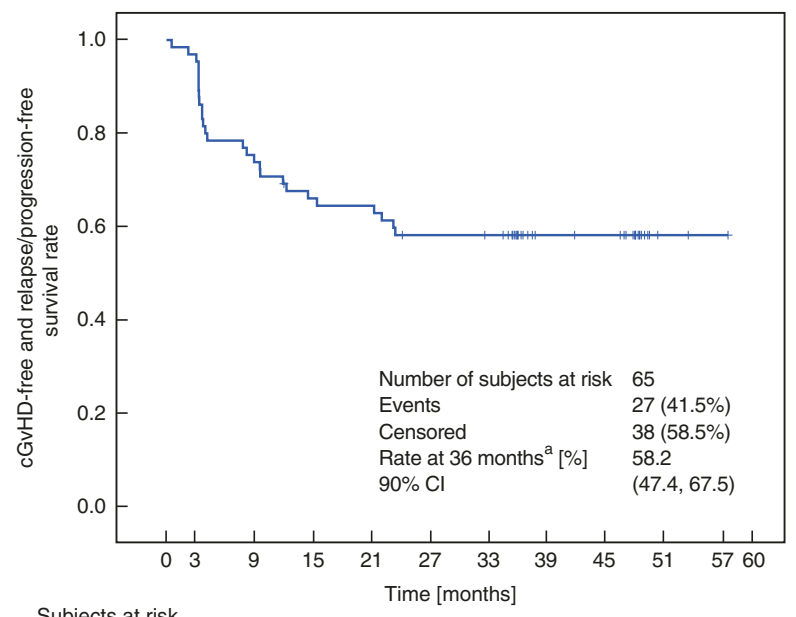

Subjects at risk

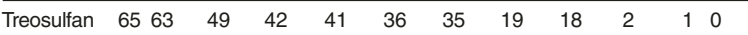

Note: 'GvHD-free' defined as no acute GvHD of at least grade III and no moderate/severe chronic GvHD. 'Chronic GvHD-free' defined as no moderate/severe chronic GvHD. Based on Kaplan-Meier estimates

Fig. 3 Kaplan-Meier estimates of (a) GvHD-free and relapse/progression-free survival and (b) chronic GvHD-free and relapse/progression-free survival.

regimens [2-5]. Overall, the 36-month relapse rate was low $(21.7 \%)$, although three patients with JMML relapsed between 6 and 9 months post transplant. Disease recurrence is known to be particularly high in patients with JMML given an allograft, but the percentage of relapse seems to be higher than that reported using the busulfan/cyclophosphamide/ melphalan regimen [32]. However, due to the very low number of JMML patients, no conclusions can be drawn at this point in time. On the other hand, the 36-month relapse incidence of $26.1 \%$ for the ALL subgroup (23 patients) is probably comparable to that of standard TBI-based regimens. 


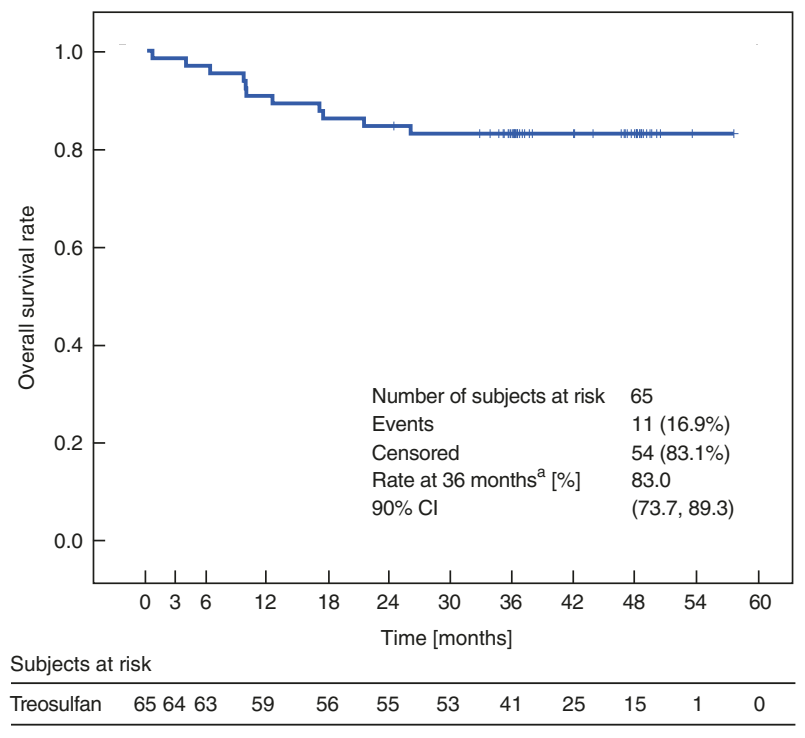

${ }^{\mathrm{a}}$ Based on Kaplan-Meier estimates

Fig. 4 Kaplan-Meier estimate of overall survival.

Table 4 Frequency of patients with treatment emergent adverse events of at least CTCAE grade III in at least $10 \%$ of patients by System Organ Class and Preferred Term (MedDRA 20.0).

\begin{tabular}{|c|c|}
\hline CTCAE System Organ Class CTCAE Term & Treosulfan $(N=65)$ \\
\hline Subjects with any event & $50(76.9 \%)$ \\
\hline \multicolumn{2}{|l|}{ Gastrointestinal disorders } \\
\hline Any event & $37(56.9 \%)$ \\
\hline Mucositis—oral & $28(43.1 \%)$ \\
\hline Nausea & $11(16.9 \%)$ \\
\hline Vomiting & $11(16.9 \%)$ \\
\hline Diarrhea & $10(15.4 \%)$ \\
\hline Dysphagia & $2(3.1 \%)$ \\
\hline Abdominal pain & $1(1.5 \%)$ \\
\hline Esophageal pain & $1(1.5 \%)$ \\
\hline Typhlitis & $1(1.5 \%)$ \\
\hline Upper gastrointestinal hemorrhage & $1(1.5 \%)$ \\
\hline \multicolumn{2}{|l|}{ Infections and infestations } \\
\hline Any event & $28(43.1 \%)$ \\
\hline Infections and infestations-other, specify & $20(30.8 \%)$ \\
\hline Catheter-related infection & $6(9.2 \%)$ \\
\hline Sepsis & $4(6.2 \%)$ \\
\hline Bladder infection & $3(4.6 \%)$ \\
\hline Urinary tract infection & $3(4.6 \%)$ \\
\hline Encephalitis infection & $1(1.5 \%)$ \\
\hline Hepatitis viral & $1(1.5 \%)$ \\
\hline Laryngitis & $1(1.5 \%)$ \\
\hline Skin infection & $1(1.5 \%)$ \\
\hline Soft tissue infection & $1(1.5 \%)$ \\
\hline Upper respiratory infection & $1(1.5 \%)$ \\
\hline
\end{tabular}

Absolute and relative frequencies of subjects with event relative to the total number of subjects $(N)$.
Numerically, it might be slightly higher compared with the data published by Peters et al. [2]. The value of TBI-based and chemotherapy-based conditioning in childhood ALL is currently being investigated in an international controlled phase III trial (EudraCT No.: 2012-003032-22; ClinicalTrials.gov Identifier: NCT01949129). The relapse incidence of $17.2 \%$ at 36 months for the 29 AML patients and of $0 \%$ for the 10 MDS patients compares favorably with that reported for busulfan-based conditioning treatments [2, 33, 34]. Excellent results of the FTT regimen in children with AML (low relapse rate and reduced toxicity) warrant assessing this regimen in a prospective randomized pediatric alloHSCT trial in Europe, comparing busulfan- and treosulfan-based conditioning regimens for AML.

All patients achieved neutrophil engraftment and 98.4\% of patients had a complete donor chimerism by day +28 post transplant. While neutrophil engraftment was comparable to that of previous reports $[12,20,31]$, no prospective trial data on chimerism have been previously reported in children with malignant disorders who received conditioning with FTT. Hence, this study provides confirmation of the myeloablative potential of a FTT conditioning regimen, which results in an excellent rate of complete donor-type chimerism.

There were no primary graft failures. One ALL patient developed secondary poor graft function with decreasing blood cell counts associated with a viral illness despite $100 \%$ donor chimerism and received a stem cell boost.

The incidence of liver toxicity was relatively low with only one case $(1.5 \%)$ of grade II HSOS, which resolved under appropriate therapy, compared with an up to $22 \%$ HSOS incidence reported in busulfan-containing regimens $[3,35]$. Moreover, skin and subcutaneous tissue disorders of at least CTCAE grade III were within an acceptable range (12.3\%) despite the intensification of the regimen with the addition of thiotepa. Just over half of the patients developed gastrointestinal (GI) AEs of at least CTCAE grade III, while oral mucositis was most prominent (43.1\%). Compared with the data published by Boztug et al. [20], GI toxicity was relatively frequent, but not life-threatening, and was probably promoted by the addition of thiotepa in the vast majority of patients.

Unlike previous reports [22-25], we observed a rather limited variability in interindividual PKs of treosulfan. The BSA-banded dose calculation applied in this trial achieved equivalent treosulfan exposure (AUC, $C_{\max }$ ) in all dose groups. In the dose subgroups, the differences in outcome parameters, such as overall survival, were therefore, probably not due to a higher treosulfan exposure, but may be related to specific patient-, graft-, and/or underlying disease characteristics. The wide age range of patients included in this trial (from 28 days to 17 years of age) is reflected by the increase in treosulfan plasma clearance and volume of 
Table 5 Pharmacokinetic results of treosulfan stratified by BSAdependent dose group (noncompartmental analysis).

\begin{tabular}{llll}
\hline Mean $\pm \mathrm{SD}, t_{\text {max }}:$ median (range) & $10 \mathrm{~g} / \mathrm{m}^{2}$ & $12 \mathrm{~g} / \mathrm{m}^{2}$ & $14 \mathrm{~g} / \mathrm{m}^{2}$ \\
\hline$N$ & 5 & $23^{\mathrm{a}}$ & 26 \\
$C_{\max }[\mu \mathrm{g} / \mathrm{mL}]$ & $700 \pm 218$ & $634 \pm 192$ & $650 \pm 98$ \\
$t_{\max }[\mathrm{h}]$ & $2.28(2.00-2.30)$ & $2.00(2.00-2.50)$ & $2.02(2.00-2.65)$ \\
$\mathrm{AUC}_{\text {last }}[\mu \mathrm{g} \mathrm{h} / \mathrm{mL}]$ & $1686 \pm 345$ & $1599 \pm 33$ & $1848 \pm 283$ \\
$\mathrm{AUC}_{\infty}[\mu \mathrm{g} \mathrm{h} / \mathrm{mL}]$ & $1700 \pm 351$ & $1627 \pm 344$ & $1900 \pm 296$ \\
$t_{1 / 2 \text { term }}[\mathrm{h}]$ & $1.15 \pm 0.12$ & $1.38 \pm 0.21$ & $1.59 \pm 0.18$ \\
$\mathrm{CL}[\mathrm{L} / \mathrm{h}]$ & $2.33 \pm 0.60$ & $5.3 \pm 1.35$ & $10.94 \pm 2.41$ \\
$V_{d}[\mathrm{~L}]$ & $3.86 \pm 1.11$ & $10.78 \pm 3.69$ & $25.24 \pm 6.64$ \\
\hline
\end{tabular}

${ }^{\mathrm{a}} N=25$ for $\mathrm{AUC}_{\infty}, \mathrm{t}_{1 / 2 \text { term }}, \mathrm{CL}, V_{d}$.

$S D$ standard deviation, $t_{\mathrm{ma}}$ time to reach maximum plasma concentration, $N$ number of subjects, $C_{\max }$ maximum plasma concentration, $h$ hour, $A U C$ area under the curve, $A U C_{\text {las }}$ AUC from time 0 to the time of the last measurable plasma concentration, $A U C_{\infty}$ AUC from time 0 to infinite time, $t_{1 / 2 \text { term }}$ apparent terminal elimination half-life, $C L$ total clearance; $V_{d}$ volume of distribution. distribution within the different dose groups. Apparently, this observation is not related to treosulfan dose, but rather to the age-related differences in organ function maturation that are taken into account in the BSA-dependent dose calculation. Therefore, the strict application of the individual BSA-dependent treosulfan dose calculation should remain valid for the pediatric population [26].

There are several limitations to this prospective phase II study. Only a small number of patients were treated, especially in the MDS and JMML subgroups. Consequently, the poor outcome reported for JMML patients should be treated with caution. However, at least one JMML patient was considered at increased risk due to his second alloHSCT procedure.

The NRM, incidence of early toxicities, and donor chimerism, though, are likely to remain stable beyond this reported 36-month observation period. We can thus, safely conclude that FTT conditioning achieves high rates of engraftment with relatively low toxicity. Based on these and other clinical data, the European Commission has most recently approved treosulfan for conditioning in pediatric patients older than 1 month with malignant diseases [36].

We conclude that treosulfan-based conditioning with BSA-adapted dosing is safe and effective in pediatric patients with hematological malignancies. The cumulative incidences of OS and NRM compare favorably with those reported for other conditioning regimens. Treosulfan/fludarabine/thiotepa is, therefore, recommended as a suitable myeloablative preparative treatment for this pediatric patient population.

Acknowledgements The authors would like to thank the nursing staff and all parents/children who gave consent and participated in this trial. The trial was funded by medac GmbH (Wedel, Germany), the sponsor of the clinical phase II trial. The authors wrote the first draft of the paper, and all contributed to subsequent drafts and made the decision to submit the paper for publication. The principal and the corresponding authors had full access to patients' data and vouch for the veracity and completeness of the data and analyses (Funded by medac $\mathrm{GmbH}$, MC-FludT.17/M, EudraCT No.: 2013-003604-39; Clinicaltrials.gov identifier: NCT02333058).

\section{Compliance with ethical standards}

Conflict of interest KK has received research funding from medac $\mathrm{GmbH}$, Sanofi, and other travel grants. $\mathrm{PB}$ has received research funding and patents and royalties from medac $\mathrm{GmbH}$, research funding from Riemser and Neovii. He also received compensation from Cellgene and Novartis for his consultations. In addition, he received compensation from Novartis for Speakers Bureau. BG received honoraria from Jazz Pharmaceuticals. KP received funding from medac $\mathrm{GmbH}$ and other funding for EBMT conference fees and accommodation. Prof. KW S received research funding and travel grants from medac $\mathrm{GmbH}$ and Aventis-Behring. SC received honoraria for his consultations from Gentium and Jazz Pharmaceuticals. RB received travel grants from medac $\mathrm{GmbH}$ and Neovii and is on Bluebird Bio's advisory board. FL received funding for EBMT/ASH conference fees and accommodation as well as speakers bureau from medac GmbH. AV is on the advisory board for Pfizer, medac $\mathrm{GmbH}$, Novartis, Amgen, and Jazz Pharmaceuticals and also received other funding from them. $\mathrm{CH}, \mathrm{AKM}$, and $\mathrm{JB}$ are employees of medac $\mathrm{GmbH}$. JB has licensed an employee's invention (PCT/EP00/10871) to medac $\mathrm{GmbH}$.

Publisher's note Springer Nature remains neutral with regard to jurisdictional claims in published maps and institutional affiliations.

Open Access This article is licensed under a Creative Commons Attribution 4.0 International License, which permits use, sharing, adaptation, distribution and reproduction in any medium or format, as long as you give appropriate credit to the original author(s) and the source, provide a link to the Creative Commons license, and indicate if changes were made. The images or other third party material in this article are included in the article's Creative Commons license, unless indicated otherwise in a credit line to the material. If material is not included in the article's Creative Commons license and your intended use is not permitted by statutory regulation or exceeds the permitted use, you will need to obtain permission directly from the copyright holder. To view a copy of this license, visit http://creativecommons. org/licenses/by/4.0/. 


\section{References}

1. Niemeyer CM, Kratz CP. Paediatric myelodysplastic syndromes and juvenile myelomonocytic leukaemia: molecular classification and treatment options. Br J Haematol. 2008;140:610-24. https:// doi.org/10.1111/j.1365-2141.2007.06958.x.

2. Peters C, Schrappe M, Stackelberg A, von Schrauder A, Bader P, Ebell W, et al. Stem-cell transplantation in children with acute lymphoblastic leukemia: a prospective international multicenter trial comparing sibling donors with matched unrelated donors-The ALL-SCT-BFM-2003 trial. J Clin Oncol. 2015;33:1265-74. https://doi.org/10.1200/JCO.2014.58.9747.

3. Beier R, Albert MH, Bader P, Borkhardt A, Creutzig U, Eyrich M, et al. Allo-SCT using BU, CY and melphalan for children with AML in second CR. Bone Marrow Transplant. 2013;48:651-6. https://doi.org/10.1038/bmt.2012.204.

4. Balduzzi A, Valsecchi MG, Silvestri D, Locatelli F, Manfredini L, Busca A, et al. Transplant-related toxicity and mortality: an AIEOP prospective study in 636 pediatric patients transplanted for acute leukemia. Bone Marrow Transplant. 2002;29:93-100. https://doi.org/10.1038/sj.bmt.1703337.

5. Bresters D, van Gils ICM, Kollen WJW, Ball LM, Oostdijk W, van der Bom JG, et al. High burden of late effects after haematopoietic stem cell transplantation in childhood: a single-centre study. Bone Marrow Transplant. 2010;45:79-85. https://doi.org/ 10.1038/bmt.2009.92.

6. Shimoni A, Labopin M, Savani B, Hamladji R-M, Beelen D, Mufti $\mathrm{G}$, et al. Intravenous busulfan compared with treosulfan-based conditioning for allogeneic stem cell transplantation in acute myeloid leukemia: a study on behalf of the acute leukemia working party of european society for blood and marrow transplantation. Biol Blood Marrow Transplant. 2018;24:751-7. https://doi.org/10. 1016/j.bbmt.2017.12.776.

7. Nagler A, Labopin M, Beelen D, Ciceri F, Volin L, Shimoni A, et al. Long-term outcome after a treosulfan-based conditioning regimen for patients with acute myeloid leukemia: a report from the Acute Leukemia Working Party of the European Society for Blood and Marrow Transplantation. Cancer. 2017;123:2671-9. https://doi.org/10.1002/cncr.30646.

8. Ruutu T, Volin L, Beelen DW, Trenschel R, Finke J, Schnitzler $\mathrm{M}$, et al. Reduced-toxicity conditioning with treosulfan and fludarabine in allogeneic hematopoietic stem cell transplantation for myelodysplastic syndromes: final results of an international prospective phase II trial. Haematologica. 2011;96:1344-50. https:// doi.org/10.3324/haematol.2011.043810.

9. Kröger N, Bornhäuser M, Stelljes M, Pichlmeier U, Trenschel R, Schmid C, et al. Allogeneic stem cell transplantation after conditioning with treosulfan, etoposide and cyclophosphamide for patients with ALL: a phase II-study on behalf of the German Cooperative Transplant Study Group and ALL Study Group (GMALL). Bone Marrow Transplant. 2015;50:1503-7. https:// doi.org/10.1038/bmt.2015.202.

10. Casper J, Knauf W, Kiefer T, Wolff D, Steiner B, Hammer U, et al. Treosulfan and fludarabine: a new toxicity-reduced conditioning regimen for allogeneic hematopoietic stem cell transplantation. Blood. 2004;103:725-31. https://doi.org/10.1182/blood-2002-11-3615.

11. Beelen DW, Trenschel R, Stelljes M, Groth C, Masszi T, Reményi $\mathrm{P}$, et al. Treosulfan or busulfan plus fludarabine as conditioning treatment before allogeneic haemopoietic stem cell transplantation for older patients with acute myeloid leukaemia or myelodysplastic syndrome (MC-FludT.14/L): a randomised, non-inferiority, phase 3 trial. Lancet Haematol. 2019:e28-39. https://doi. org/10.1016/S2352-3026(19)30157-7.

12. Slatter MA, Rao K, Abd Hamid IJ, Nademi Z, Chiesa R, Elfeky R, et al. Treosulfan and fludarabine conditioning for hematopoietic stem cell transplantation in children with primary immunodeficiency: UK experience. Biol Blood Marrow Transplant. 2018;24:529-36. https://doi.org/10.1016/j.bbmt.2017.11.009.

13. Burroughs LM, Shimamura A, Talano J-A, Domm JA, Baker KK, Delaney $\mathrm{C}$, et al. Allogeneic hematopoietic cell transplantation using treosulfan-based conditioning for treatment of marrow failure disorders. Biol Blood Marrow Transplant. 2017;23:1669-77. https://doi.org/10.1016/j.bbmt.2017.06.002.

14. Marzollo A, Calore E, Tumino M, Pillon M, Gazzola MV, Destro $\mathrm{R}$, et al. Treosulfan-based conditioning regimen in sibling and alternative donor hematopoietic stem cell transplantation for children with sickle cell disease. Mediterr J Hematol Infect Dis. 2017;9:e2017014. https://doi.org/10.4084/MJHID.2017.014.

15. Morillo-Gutierrez B, Beier R, Rao K, Burroughs L, Schulz A, Ewins A-M, et al. Treosulfan-based conditioning for allogeneic HSCT in children with chronic granulomatous disease: a multicenter experience. Blood. 2016;128:440-8. https://doi.org/10. 1182/blood-2016-03-704015.

16. Slatter MA, Boztug H, Pötschger U, Sykora K-W, Lankester A, Yaniv I, et al. Treosulfan-based conditioning regimens for allogeneic haematopoietic stem cell transplantation in children with nonmalignant diseases. Bone Marrow Transplant. 2015;50:1536-41. https://doi.org/10.1038/bmt.2015.171.

17. Strocchio L, Zecca M, Comoli P, Mina T, Giorgiani G, Giraldi E, et al. Treosulfan-based conditioning regimen for allogeneic haematopoietic stem cell transplantation in children with sickle cell disease. Br J Haematol. 2015;169:726-36. https://doi.org/10. 1111/bjh.13352.

18. Dinur-Schejter Y, Krauss AC, Erlich O, Gorelik N, Yahel A, Porat I, et al. Bone marrow transplantation for non-malignant diseases using treosulfan-based conditioning. Pediatr Blood Cancer. 2015;62:299-304. https://doi.org/10.1002/pbc.25267.

19. Maschan M, Shelikhova L, Ilushina M, Kurnikova E, Boyakova E, Balashov D, et al. TCR-alpha/beta and CD19 depletion and treosulfan-based conditioning regimen in unrelated and haploidentical transplantation in children with acute myeloid leukemia. Bone Marrow Transplant. 2016;51:668-74. https://doi.org/10. 1038/bmt.2015.343.

20. Boztug H, Sykora K-W, Slatter M, Zecca M, Veys P, Lankester A, et al. European Society for blood and marrow transplantation analysis of treosulfan conditioning before hematopoietic stem cell transplantation in children and adolescents with hematological malignancies. Pediatr Blood Cancer. 2016;63:139-48. https://doi. org/10.1002/pbc. 25764 .

21. Bernardo ME, Piras E, Vacca A, Giorgiani G, Zecca M, Bertaina A, et al. Allogeneic hematopoietic stem cell transplantation in thalassemia major: results of a reduced-toxicity conditioning regimen based on the use of treosulfan. Blood. 2012;120:473-6. https://doi.org/10.1182/blood-2012-04-423822.

22. van der Stoep MYEC, Bertaina A, Brink MHten, Bredius RG, Smiers FJ, Wanders DCM, et al. High interpatient variability of treosulfan exposure is associated with early toxicity in paediatric HSCT: a prospective multicentre study. $\mathrm{Br} \mathrm{J}$ Haematol. 2017;179:772-80. https://doi.org/10.1111/bjh.14960.

23. Romański M, Wachowiak J, Główka FK. Treosulfan pharmacokinetics and its variability in pediatric and adult patients undergoing conditioning prior to hematopoietic stem cell transplantation: current state of the art, in-depth analysis, and perspectives. Clin Pharmacokinet. 2018;57:1255-65. https://doi.org/10.1007/s40262018-0647-4.

24. Chiesa R, Standing JF, Winter R, Nademi Z, Chu J, Pinner D, et al. Proposed therapeutic range of treosulfan in reduced toxicity pediatric allogeneic hematopoietic stem cell transplant conditioning: results from a prospective trial. Clin Pharmacol Ther. 2019. https:// doi.org/10.1002/cpt.1715. 
25. van der Stoep MYEC, Zwaveling J, Bertaina A, Locatelli F, Guchelaar HJ, Lankester AC, et al. Population pharmacokinetics of treosulfan in paediatric patients undergoing hematopoietic stem cell transplantation. Br J Clin Pharm. 2019;85:2033-44. https:// doi.org/10.1111/bcp.13995.

26. Reijmers T, Hemmelmann C, Sykora K-W, Vora A, Kehne J, Möller A-K, et al. Population PK-modelling of treosulfan in paediatric allogeneic transplant patients. Twenty-seventh Annual Meeting of the Population Approach Group in Europe (page), Montreux; 2018.

27. McCurdy SR, Kasamon YL, Kanakry CG, Bolaños-Meade J, Tsai H-L, Showel MM, et al. Comparable composite endpoints after HLA-matched and HLA-haploidentical transplantation with posttransplantation cyclophosphamide. Haematologica. 2017;102: 391-400. https://doi.org/10.3324/haematol.2016.144139.

28. Jones RJ, Lee KS, Beschorner WE, Vogel VG, Grochow LB, Braine $\mathrm{HG}$, et al. Venoocclusive disease of the liver following bone marrow transplantation. Transplantation. 1987;44:778-83.

29. Bearman SI, Appelbaum FR, Buckner CD, Petersen FB, Fisher LD, Clift RA, et al. Regimen-related toxicity in patients undergoing bone marrow transplantation. J Clin Oncol. 1988;6:1562-8. https://doi.org/10.1200/JCO.1988.6.10.1562.

30. Maiolica A, Meunier L, Bialleck S, Guhde I, Wood S, Struwe P. Bioanalytical determination of treosulfan and its active metabolites. EBF 7th Open Meeting, Barcilona; 2014.

31. Nemecek ER, Hilger RA, Adams A, Shaw BE, Kiefer D, LeRademacher J, et al. Treosulfan, fludarabine, and low-dose total body irradiation for children and young adults with acute myeloid leukemia or myelodysplastic syndrome undergoing allogeneic hematopoietic cell transplantation: prospective phase II trial of the pediatric blood and marrow transplant consortium. Biol Blood
Marrow Transplant. 2018;24:1651-6. https://doi.org/10.1016/j. bbmt.2018.04.025.

32. Locatelli F, Nöllke P, Zecca M, Korthof E, Lanino E, Peters C, et al. Hematopoietic stem cell transplantation (HSCT) in children with juvenile myelomonocytic leukemia (JMML): results of the EWOG-MDS/EBMT trial. Blood. 2005;105:410-9. https://doi. org/10.1182/blood-2004-05-1944.

33. Lucchini G, Labopin M, Beohou E, Dalissier A, Dalle JH, Cornish $\mathrm{J}$, et al. Impact of conditioning regimen on outcomes for children with acute myeloid leukemia undergoing transplantation in first complete remission. An analysis on behalf of the pediatric disease working party of the European Group for Blood and Marrow Transplantation. Biol Blood Marrow Transplant. 2017;23:467-74. https://doi.org/10.1016/j.bbmt.2016.11.022.

34. Strahm B, Nöllke P, Zecca M, Korthof ET, Bierings M, Furlan I, et al. Hematopoietic stem cell transplantation for advanced myelodysplastic syndrome in children: results of the EWOG-MDS 98 study. Leukemia. 2011;25:455-62. https://doi.org/10.1038/leu. 2010.297.

35. Bartelink IH, van Reij EML, Gerhardt CE, van Maarseveen EM, Wildt A, de, Versluys B, et al. Fludarabine and exposure-targeted busulfan compares favorably with busulfan/cyclophosphamidebased regimens in pediatric hematopoietic cell transplantation: maintaining efficacy with less toxicity. Biol Blood Marrow Transplant. 2014;20:345-53. https://doi.org/10.1016/j.bbmt.2013. 11.027.

36. European Medicines Agency. Union register of medicinal products: marketing authorisation. Decision number (2019)4858 of 20 Jun 2019. 2019. https://ec.europa.eu/health/documents/ community-register/html/h1351.htm.

\section{Affiliations}

Krzysztof Kalwak $\mathbb{D}^{1} \cdot$ Monika Mielcarek ${ }^{1} \cdot$ Katharine Patrick ${ }^{2} \cdot$ Jan Styczynski $\oplus^{3} \cdot$ Peter Bader $^{4}$.

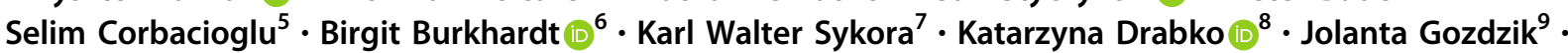

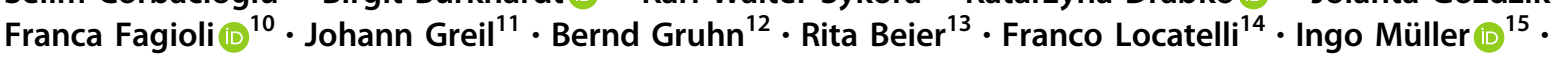
Paul Gerhardt Schlegel ${ }^{16} \cdot$ Petr Sedlacek $^{17}$ - Klaus Daniel Stachel ${ }^{18} \cdot$ Claudia Hemmelmann $^{19}$ • Ann-Kristin Möller ${ }^{19}$. Joachim Baumgart ${ }^{19} \cdot$ Ajay Vora ${ }^{20}$

1 Department of Pediatric Hematology, Oncology and Bone Marrow Transplantation, Wroclaw Medical University, Wroclaw, Poland

2 Sheffield Children's Hospital, Sheffield, UK

3 Department of Pediatric Hematology and Oncology, Collegium Medicum UMK Torun, Bydgoszcz, Poland

4 Department for Children and Adolescents, Division for Stem Cell Transplantation, Immunology and Intensive Care Medicine, Goethe University, Frankfurt, Germany

5 University Hospital of Regensburg, Regensburg, Germany

6 Department of Pediatric Hematology, Oncology and BMT, University Hospital Muenster, Muenster, Germany

7 Department of Pediatrics, Hannover Medical School, Hannover, Germany

8 Department of Pediatric Hematology, Oncology and Transplantology, Medical University of Lublin, Lublin, Poland
9 Medical College, University Children's Hospital in Cracow Jagiellonian University, Cracow, Poland

10 Children's Hospital Regina Margherita, University of Turin, Turin, Italy

11 University Children's Hospital Heidelberg, Heidelberg, Germany

12 Department of Pediatrics, Jena University Hospital, Jena, Germany

13 Depertment of Pediatrics III, University Hospital of Essen, Essen, Germany

14 IRCCS Bambino Gesú Children's Hospital, Sapienza University of Rome, Rome, Italy

15 University Medical Center Hamburg-Eppendorf, Hamburg, Germany

16 University Children's Hospital of Wuerzburg, Wuerzburg, Germany 
17 Department of Pediatric Hematology and Oncology, University Hospital Motol, Prague, Czech Republic

18 Children's Hospital, University of Erlangen, Erlangen, Germany
19 medac GmbH, Wedel, Germany

20 Great Ormond Street Hospital, London, UK 